\section{The mystery of the microscope in mud}

A rare brass microscope was discovered in mud dredged from canals in Delft, the Netherlands, in December 2014. The instrument (pictured, left) is thought to have been made by Dutch pioneer microscopist Antony van Leeuwenhoek (1632-1723; see P. Ball Nature 520, 156; 2015) and is an important find - if it is genuine. The last Leeuwenhoek microscope in public hands was

a silver instrument that sold for more than US\$500,000 in 2009.

The ten microscopes attributed to Leeuwenhoek are diminutive, comprising a biconvex lens sandwiched between two riveted body plates. A positioning screw holds a stage block and a pin to secure the specimen. A smaller screw moves the stage block to focus the image.

The Delft microscope's design and dimensions are comparable to those of a Leeuwenhoek microscope in the Boerhaave Museum in Leiden. Although the lens is abraded, it would have given about $160 \times$ magnification.

The Delft find cannot be a replica. First, it has a rounded body plate - a comparable microscope in the Boerhaave Museum is rectangular (pictured, right), and a copy would have an identical configuration. Second, my analysis of the screw thread at the Cavendish Laboratory at the University of Cambridge, UK, shows that it is unlike threads produced by modern mechanical methods. The distance between the threads (or pitch) of the main screw is 0.9 millimetres, comparable with that in authentic instruments.

I am preparing a protocol through which the production details of all existing Leeuwenhoek microscopes can be scrutinized. Scanning electron microscopy should then be able to detect any forgeries.

Brian J. Ford Cardiff University, UK.

brianjford@cardiff.ac.uk

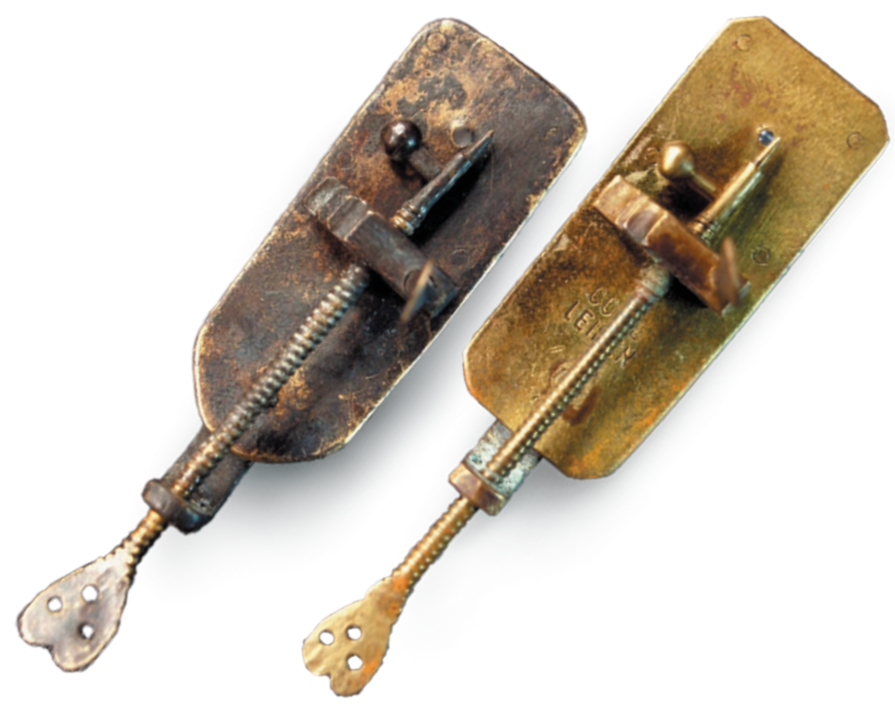

\section{Deforestation soars in the Amazon}

Deforestation of the Brazilian Amazon is on the rise and not declining as you imply (Nature 520, 20-23; 2015). Forest clearance has exploded since August 2014, according to satellite data from Brazil's National Institute for Space Research and the sustainable-development organization Imazon. Monthly clearance rates are several times those for the same months in the preceding two years.

The data on deforestation drivers in the studies you discuss predate the recent deforestation surge (D. Nepstad et al. Science 344, 1118-1123; 2014 and H. K. Gibbs et al. Science 347, 377-378; 2015). Brazil's currency, the real, is in free-fall, with no end in sight. Exchange rates against the US dollar mean that exports from Brazil are now considerably more profitable than last year, when the deforestation decline was occurring.

Prospects for the near term are not good. A key 2008 resolution from the Central Bank of Brazil, which links financing from public banks to environmental compliance, now offers only fragile protection in the face of a congress dominated by those in favour of agribusiness. Creation of new protected areas has been essentially paralysed, existing reserves continue to have their official status removed, and government expenditure on enforcing environmental laws has been cut by $72 \%$. Furthermore, political appointments are sending an anti-environmental signal to deforesters (see Nature 517, 251-252; 2015), and plans for Amazonian roads continue as fast as money allows. The "battle for the Amazon" is far from won. Philip M. Fearnside National Institute for Research in Amazonia (INPA), Manaus, Brazil. pmfearn@inpa.gov.br

\section{UK bioscientists push for crop policy}

In assessing the next generation of plant-breeding techniques such as gene editing (Nature 520, 131-132; 2015), the European Union (EU) should take into account criticisms of its current regulatory system for new crop varieties.

Last year's statement by the UK Biotechnology and Biological Sciences Research Council on genetic techniques for crop improvement suggests that EU regulations need to move beyond production methods and focus more on the benefits of newly introduced genetic traits (see go.nature. com/gsoiza).

The UK National Institutes of Bioscience, which contributed to the statement, seek prompt realization of the societal and environmental benefits of these latest technologies. They are leading efforts to ensure that the best policy decisions are being made for plant (and animal) breeding in Europe and worldwide.

David Hume National Institutes of Bioscience, UK. david.hume@roslin.ed.ac.uk

\section{Marine protection is a UK priority}

Scotland's government has responsibility for nature conservation in $61 \%$ of UK waters. As programme manager for the Marine Conservation Society in Scotland, I agree that the United Kingdom and its devolved governments should be making marine conservation a priority (see also Nature 520, 585-586; 2015).

This summer, Scotland could become a global conservation leader following proposals for Marine Protected Areas (MPAs) for highly mobile species, including minke whales and basking sharks. These areas will soon be subject to public consultation. The hope is that they will then augment the 30 Scottish MPAs designated in summer 2014. Even at some of these sites, damaging fishing activity may still be continuing (see go.nature.com/hzkdzd). Present and future governments in Scotland and Westminster must take steps to keep the ' $\mathrm{P}$ ' in MPAs.

Calum Duncan Marine Conservation Society, Edinburgh; and Scottish Environment LINK, Perth, UK.

calum.duncan@mcsuk.org

\section{CORRECTION}

The Correspondence 'Interim initiative for health in Iran' (Nature 521, 32; 2015) wrongly implied that A. A. Velayati is a volunteer for non-profit group IAPA; only H. Jamaati and S. M. Hashemian are IAPA volunteers. 